\title{
Study of the two-stage gasification process of pulverized coal with a combined countercurrent and concurrent flow system
}

\author{
Viktor Kuznetsov ${ }^{1,2}$, Mikhail Chernetskiy ${ }^{2,3, *}$ Nikolay Abaimov ${ }^{3}$, Alexandr Ryzhkov $^{3}$ \\ ${ }^{1}$ Siberian Federal University, 79 Svobodny, Krasnoyarsk, 660041, Russia \\ ${ }^{2}$ Kutateladze Institute of Thermophysics, Novosibirsk, 630090, Russia \\ ${ }^{3}$ Ural Federal University, 19 Mir Street, Yekaterinburg 620002, Russia
}

\begin{abstract}
The paper presents a numerical study of an advanced two-stage gasifier with a combined countercurrent and concurrent flow pattern and dry fuel feed system EAGLE. The Reynolds Stress model was used for the numerical simulation of turbulent flow. We have conducted studies on the influence of upper burner's inclination angle on heat and mass transfer processes in the gasifier as well as on coal conversion. It is shown that the increase in the upper burner's inclination angle in the horizontal plane allows intensifying the process of two-stage gasification.
\end{abstract}

\section{Introduction}

Use Gasification of coal is one of the most strategic pathways of coal processing. Market analysis of gasification technologies shows that the most popular are flow gasifiers, whose share is about $80 \%$ [1].

The analysis of technical solutions used in new designs of gasifiers in terms of efficiency and economy of their application in integrated gasification combined cycle (IGCC) has shown that the use of two-stage principle of the fuel conversion process is one of the upcoming trends in technology modernization. According to [2], the transition from single-stage process in the flow gasifier to two-stage process can increase the efficiency of the IGCC by almost $1 \%$.

The EAGLE-type two-stage gasifier, developed in the frameworks of the Japanese project "Coal Energy Application for Gas, Liquid and Electricity" (EAGLE) [3] is one of the original technical. In this paper, on the basis of numerical studies, using the Kuznetsk coal as a fuel, we examine the influence of several operating parameters of the EAGLE gasifier on the heat and mass transfer parameters in the gasification chamber as well as the efficiency of the gasification process.

*Corresponding author: micch@yandex.ru 


\section{Problem statement and research methods}

The operational principle of the EAGLE gasifiers is based on a hydrodynamic flow separation, providing a combined countercurrent and concurrent flow pattern (Fig.1). One advantage of this solution is reducing the required height of the reaction zone, while increasing the residence time of coal particles in the reactor. One flow, with oxygen to coal ratio close to stoichiometric value, is delivered to the lower part of the gasification chamber. While combusting, it creates the necessary temperatures for efficient proceeding of the gasification reactions. The second flow, with the lack of air, is delivered into an upper part of the chamber, where it interacts with the high temperature up flow of combustion products. Due to the lack of oxygen for complete combustion, the carbon residue transforms into gasification reaction products through the conversion process. In this work, the Kuznetsk coal was used as a gasifier fuel. Analysis of Kuznetsk coal: $\mathrm{W}^{\mathrm{a}}=5.4 \%, \quad \mathrm{~A}^{\mathrm{d}}=22.3 \%, \quad \mathrm{~V}^{\mathrm{d}}=34.7 \%, \quad \mathrm{~V}^{\mathrm{daf}}=44.7 \%, \quad \mathrm{C}^{\mathrm{daf}}=75.57 \%, \quad \mathrm{H}^{\mathrm{daf}}=5.66 \%, \quad \mathrm{~N}^{\mathrm{daf}}=1.78 \%$, $\mathrm{S}^{\mathrm{daf}}=0.55 \%, \mathrm{O}^{\mathrm{daf}}=16.44 \%, \mathrm{Q}_{\mathrm{s}}^{\mathrm{daf}}=7086 \mathrm{kcal} / \mathrm{kg}$. The estimated coal consumption is 1700 $\mathrm{t} /$ day. The dimensions of the gasification chamber are presented in Fig. 2.

For the numerical simulation of turbulent flow of an incompressible liquid we used the Reynolds equations taking into account the interfacial interaction. The Reynolds equations were closed using the Reynolds stress model (RSM). Abandoning the isotropic eddyviscosity hypothesis, the RSM closes the Reynolds-averaged Navier-Stokes equations by solving transport equations for the Reynolds stresses, together with an equation for the dissipation rate. Since the RSM accounts for the effects of streamline curvature, swirl, rotation, and rapid changes in strain rate in a more rigorous manner than one-equation and two-equation models, it has greater potential to give accurate predictions for complex flows [4]. In the present work, to describe the particles motion we used the Lagrange method. Combustion the gas phase is represents the combination of kinetic combustion model of the gas components with the eddy break-up model. The coal particle burning process was represented as the following consecutive steps: evaporation of moisture from the fuel, devolatilization and the combustion of volatile components, and combustion of the coke residue. The combustion rate of coke residue was calculated in accordance with the provisions of the classical diffusion-kinetic theory. To describe gasification processes, we included the reactions of steam-air conversion of coal into the mathematical model. Reactions and kinetic constants are presented in Table 1.

The proposed model and solution methods were previously tested for solving problems of pulverized coal combustion and gasification [5] and showed a satisfactory agreement with the experimental data on the basic process parameters in the combustion chamber.

Table 1. Specific reaction rates of combustion and gasification.

\begin{tabular}{lcccc}
\hline & Reaction & \multicolumn{2}{c}{$\mathrm{Ks}=\mathrm{A} \exp (-\mathrm{E} / \mathrm{RT})$} & References \\
\hline & & $\mathrm{m} / \mathrm{s}$ & $\mathrm{J} / \mathrm{mol}$ & \\
\hline 1. & $\mathrm{C}+\mathrm{O} 2 \rightarrow \mathrm{CO}+\mathrm{CO} 2$ & $3.3 \cdot 10^{4}$ & 135756 & D.M. Khzmalyan (1977) \\
\hline 2. & $\mathrm{C}+\mathrm{H} 2 \mathrm{O} \rightarrow \mathrm{CO}+\mathrm{H} 2$ & $1.6 \cdot 10^{4}$ & 181427 & V.F. Yudin (1957) \\
\hline 3. & $\mathrm{C}+\mathrm{CO} 2 \rightarrow 2 \mathrm{CO}$ & $3.5 \cdot 10^{4}$ & 140365 & V.A. Parilov (1971) \\
\hline
\end{tabular}

\section{Results and discussion}

As was shown earlier [6], the use of the RSM turbulence model enables more accurate description of aerodynamics in the twisted flow pulverized-coal chamber. The aerodynamics features in the combustion chamber strongly affect heat and mass exchange processes and pulverized coal fuel gasification. The gas flow direction influences the motion trajectory and residence time of the coal particles in the chamber. Several variants 
of the two-stage gasification process organization were investigated. The influence of upper burner's inclination angle in the horizontal (angle $\alpha$ ) and vertical plane (angle $\beta$ ) on heat and -mass exchange processes, coal particles conversion and syngas composition is researched (Fig. 3.4). The initial calculated data are presented in Table 2.

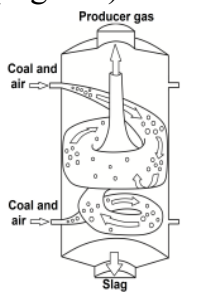

Fig. 1. EAGLE gasifier

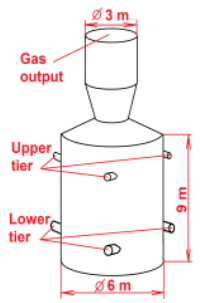

Fig. 2. Feeding diagram and gasifier dimensions at a flow rate of 1700 $\mathrm{t} / \mathrm{h}$

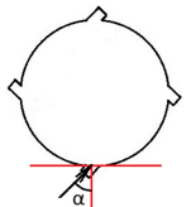

Fig. 3. Inclination angle of burners in the horizontal plane of the upper tier

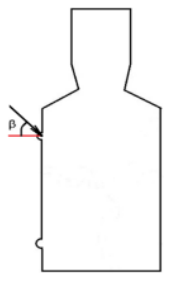

Fig. 4. Inclination angle of burners in the vertical plane of the upper tier

Table 2. Gasification process options in the chamber.

\begin{tabular}{cccc}
\hline Option & 1 & 2 & 3 \\
\hline Inclination angle of upper burners $\alpha,^{\circ}$ & 30 & 45 & 60 \\
\hline${\text { Inclination angle of upper burners } \beta,^{\circ}}^{\circ}$ & 0 & 0 & 0 \\
\hline
\end{tabular}

Below are the results of calculations. It can be seen that there is a significant effect of the upper burner's inclination angles in the horizontal plane on the heat-mass transfer processes in the gasifier. The increasing of upper burner's inclination angle leads to a decrease of the maximum temperatures in the gasifier (Fig. 5). This is explained by the difference of downstream flow velocity near the gasifier walls. Comparison of the axial velocity profiles (Fig. 5a) across the gasifier at $2.5 \mathrm{~m}$ height shows that angle $\alpha=30^{\circ}$, in comparison with the angle $\alpha$ of 45 and $60^{\circ}$, leads to less intensive gases motion down along the gasifier walls. The downward flow velocity at an angle $\alpha=30^{\circ}$ does not exceed $4(\mathrm{~m} / \mathrm{s})$, and at an angle $\alpha=60^{\circ}$ it reaches $8-9(\mathrm{~m} / \mathrm{s})$. The low temperatures in the chamber at $\alpha=$ $60^{\circ}$ (Fig. 5d-5f) can be explained by more intense gas flow downward from the upper stage of the burners, promotes their better mixing with combustion products of the lower burners and more intensive gasification endothermic reactions.

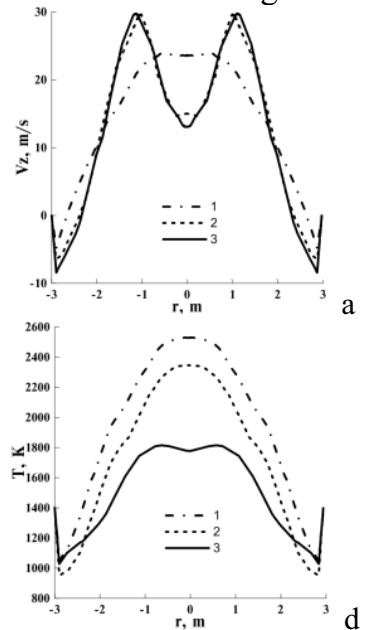

$\mathrm{H}=2.5 \mathrm{~m}$
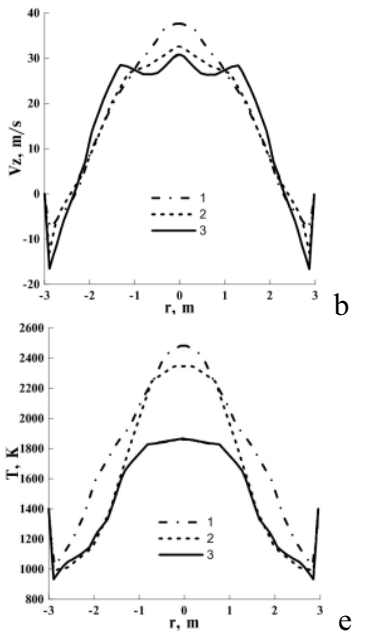

$\mathrm{H}=4.5 \mathrm{~m}$
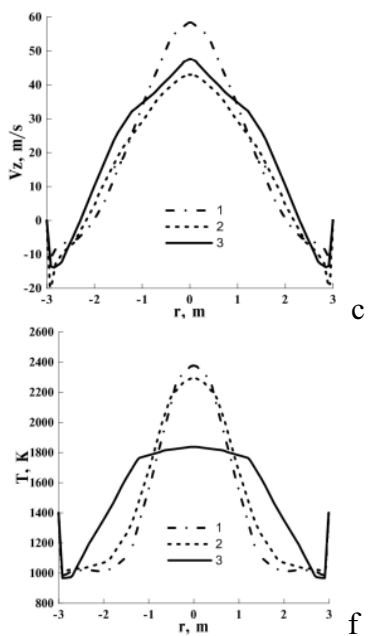

$\mathrm{H}=6.5 \mathrm{~m}$

Fig. 5. Radial distribution of axial velocity and temperature over the chamber height. 
Comparison of the carbon particles concentration across the gasifier at a $2.5 \mathrm{~m}$ height shows that at the angle $\alpha=60^{\circ}$, in comparison with the angles $\alpha$ equal to 30 and $45^{\circ}$, a larger amount $\left(0.8 \mathrm{~kg} / \mathrm{m}^{3}\right)$ of fuel near the walls is observed (Fig.6a) . In the upper part of the gasifier, for an option at $\alpha=30^{\circ}$, the concentration of coal particles is higher $-4.5 \mathrm{~kg} / \mathrm{m}^{3}$ (Fig.6c). Thus, an increase in the upper burner's inclination angle results in a more intensive descending movement of coal fuel from the upper burners to the lower part of the gasifier.

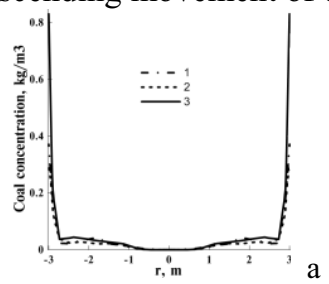

$\mathrm{H}=2.5 \mathrm{~m}$

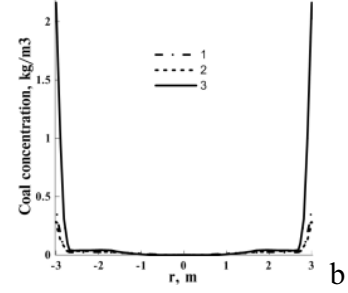

$\mathrm{H}=4.5 \mathrm{~m}$

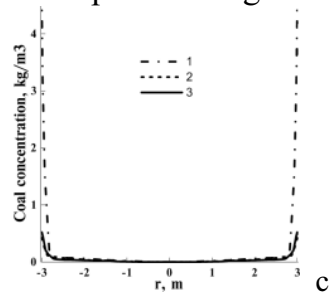

$\mathrm{H}=6.5 \mathrm{~m}$

Fig. 6. Radial distribution of coal concentration over the chamber height.

Comparative analysis of the calculation results showed that an increase in angle $\alpha$ leads to increase of carbon conversion from $82.51 \%$ to $99.05 \%$ and increase of chemical efficiency (cold gas efficiency) from $80.60 \%$ to $87.10 \%$.

\section{Conclusion}

Numerical studies of advanced two-stage flow gasifier have been carried out for Kuznetsk coal gasification.

It is shown that the increase of the angle of rotation of the burners of the upper tier in a horizontal plane increases coal conversion and chemical efficiency.

The increase of the angle $\alpha$ leads to intensification of the two-stage gasification process and allows reducing the gasifier height without decreasing the syngas heating value.

Problem statement and results analysis were carried out at the Ural Federal University and financially supported by the Russian Science Foundation (project no. 14-19-00524).

The development of methods for mathematical modeling and calculations was carried out with the financial support of the Ministry of Education and Science of the Russian Federation under the Grant Agreement No. 14.607.21.0150 (Unique identifier of the RFMEFI60716X0150)

\section{References}

1. C. Higman, Proceedings of the International Pittsburgh Coal Conference, Beijing, China, September 16-19, 2013

2. C. Higman, M. Burgt, Gasification (Elsevier Science, 2008)

3. F. Kiso, T. Akiyama, A. Morihara, K. Takahashi, E. Kida, J. Iritani, et al., Proceedings of the 25th International Conference on Coal Utilization \& Fuel Systems, Clearwater, $F L$, USA, 2000

4. B.E. Launder, G.J. Reece, W. Rodi, J. Fluid Mech. 68, 537 (1975)

5. N.A. Abaimov, A.F. Ryzhkov, Thermal Eng. 62, 767 (2015)

6. V.A. Kuznetsov, N.S. Chernetskaya, M.Yu. Chernetskiy, J. Phys.: Conf. Ser. 754, 112006 (2016) 